\title{
Study on the Presence and Influence of Phenolic Compounds in Callogenesis and Somatic Embryo Development of Cocoa (Theobroma cacao L.)
}

\author{
Sulistyani Pancaningtyas ${ }^{1 *}$ \\ 1) Indonesian Coffee and Cocoa Research Institute, Jl. PB Sudirman No. 90, Jember 68118, Indonesia \\ ${ }^{*}$ Corresponding author: listya1606@gmail.com
}

\begin{abstract}
Cocoa (Theobroma cacao L.) like most tropical trees is recalcitrant which may hamper somatic embryogenesis process of plant. High phenolic content, their oxidation and accumulation in cocoa tissue may inhibit further development. This study was conducted to investigate the composition of phenolic compounds in cocoa flower and leaves, and their changes throughout somatic embryogenesis process. Calli were induced in cacao flower and leaf explants on a half-strength Murashige and Skoog medium containing $30 \mathrm{~g} \mathrm{~L}^{-1}$ glucose and combination of 2,4 dichlorophenoxyacetic acid with kinetin. Total polyphenol content was observed on Sulawesi 1 cocoa clone. Embryogenic and non-embryogenic calli were also compared. The percentage of callus production from flower tissue was $85 \%$, percentage of embryogenic callus $40 \%$, although the percentage of somatic embryo production from embryogenic callus was $70 \%$. The regeneration of callus into somatic embryos was followed by declining in phenol content and an increase in peroxidase. The synthesis kinetics for these compounds in calli, under different somatic embryogenesis conditions, revealed a higher concentration under non-embryogenic conditions. Therefore the presence of phenolic compounds can decrease production of somatic embryo.
\end{abstract}

Keywords: Theobroma cacao L., polyphenol, somatic embryo, callus, flavonoid, cathekin, in vitro recalcitance

\section{INTRODUCTION}

Theobroma cacao L. is a tropical tree, with origins in the Amazon basin, and currently cultivated throughout the tropics to supply the global demand for cocoa, the main ingredient for the manufacture of chocolate. A high degree of yield variation is a general characteristic of cacao plantations worldwide, due in part to the predominant use of seed propagation. Cocoa is mostly self-incompatible and highly heterozygous tree crop (Figueira \& Janick, 1995). Cocoa breeders continue to face the problem of high heterogenity between individuals derived from one cross, and heterogenous transmission of genetic traits to the progeny. Improvements made by plant breeders are often rapidly lost, as farmers propagate plants through seeds, and segregation results in a highly heterozygous population of plants. Modern biotechnology offers suitable and new approaches to speed up the development and deployment of genetically improved genotypes. The use of somatic embryogenesis from floral parts is generally efficient for micropropagation technique to multiply elite cocoa planting materials

PELITA PERKEBUnAN, Volume 31, Number 1, Edition April 2015 
(Lopez-Baez et al., 1993; Alemanno et al., 1996; Li et al., 1998).

However, cocoa is generally a recalcitrant species. Recalcitrance is defined as the inability of plant cells, tissue and organs to respond readily to tissue culture (Benson, 2000). One of factors often considered as a component in vitro recalcitrance is a high phenolic content and oxidation of these compounds. Cocoa (T. cacao) like most tropical tress is recalcitrant in tissue culture. Naturally, cocoa contains large amounts of polyphenolic compounds (Griffiths, 1958; Kim \& Keeney, 1983). Their oxidation could be a limiting factor in preventing proper tissue multiplication and maintenance. In cocoa tissue culture, very little information on biochemical alteration during cell differentiation. Generally calli from this species accumulate high amount of phenolic compounds which probably impair further development. Phenols are known to be potent modifiers of peroxidase and IAA-oxidase activities (Galston et al., 1968).

The presence of phenolic compounds causing death of explants has been another important problem of tissue cultures of woody perennials (Compton \& Preece, 1986). Some of these exudates appear as a reaction to injury and/or infection. In tissue culture they appear after tissue excision and several times aggravated by growth media constituents (Seneviratne \& Wijesekara, 1996). Tissue blackening occurs due to action of copper-containing oxidase enzymes: polyphenoloxidases like tyrosinases, which are released or synthesized in oxidative conditions after tissue wounding and they oxidize o-diphenols released due to cellular wounding to o-quinones (Scalbert et al., 1988; Marks \& Simpson, 1990). The onset of tissue browning has been found to be associated with changes in protein pattern, amino acid content, ethylene production and the occurrence of saccharose and accumulation of starch (Lindfors et al., 1990). These changes eventually lead to growth inhibition or death of explants. Other types of phenolic exudates appear at the end of incubation period and are apparently products of dying cells (Seneviratne \& Wijesekara, 1996). Several factors in the growth and culture conditions of the donor tissues have been tested, that may in later steps of the establishment of tissue cultures cause browning. In vitro formation of phenolic acids from explants diminished when donor tissues were preincubated on a medium with or without mineral salts treated with BA $(200 \mathrm{mg} / \mathrm{L})$ or PVPP, ascorbic acid, cysteine, or citric acid (Keskitalo, 1999). Accumulation of phenolics is most obviously associated with the developmental stage of the plant and season, which was shown with woody species. In addition, culturing in vitro plantlets under low light intensity has given good results (Keskitalo, 1999).

The objectives of the reported work were to investigate the composition of phenolic compounds in several different somatic embryogenesis stages and its influence on in vitro propagation of cocoa.

\section{MATERIALS AND METHODS}

Calli were induced from cocoa cotyledon and floral bud of Sulawesi 1 clone. Cocoa cotyledons, staminodes and petals were cultured on Murashige and Skoog (MS) medium supplemented with glycine $(2 \mathrm{mg}$ $\left.\mathrm{L}^{-1}\right)$, lysin $\left(0.4 \mathrm{mg} \mathrm{L}^{-1}\right)$, leucine $\left(0.4 \mathrm{mg} \mathrm{L}^{-1}\right)$, arginine $\left(0.4 \mathrm{mg} \mathrm{L}^{-1}\right)$, tryptophan $(0.2 \mathrm{mg}$ $\left.\mathrm{L}^{-1}\right), 2,4$-dichlorophenoxyacetic acid, kinetin $\left(0.25 \mathrm{mg} \mathrm{l}^{-1}\right)$ and sucrose $\left(40 \mathrm{~g} \mathrm{~L}^{-1}\right)$. Somatic embryogenesis were induced by transferring 4-weeks old callus in a half strength Murashige and Skoog medium containing adenin and $30 \mathrm{~g} \mathrm{~L}^{-1}$ sucrose. On this medium, somatic embryos were regenerated from callus. 


\section{Sample preparation}

Samples were dried at room temperature, then ground to fine powder which was then macerated with $70 \%$ ethanol for one week. Samples were centrifuged and $100 \mathrm{mg}$ of freeze-dried pineapple pulp were extracted overnight by $10 \mathrm{~mL}$ methanol at $4^{\circ} \mathrm{C}$ with a blender. Samples were centrifuged at $3000 \mathrm{rpm}$ for $10 \mathrm{~min}$. The supernatant was collected and cleaned up. The cartridge assembly was conditioned with $10 \mathrm{~mL}$ of methanol, followed by $10 \mathrm{~mL}$ of distilled water. The sample was directly loaded onto the cartridge and washed with $10 \mathrm{~mL}$ of distilled water. The attached cartridges were eluted with $10 \mathrm{~mL}$ methanol. These eluates were collected in a flask and then evaporated under Speed Vac to dry. Every extract sample was dissolved in $5 \mathrm{~mL}$ methanol, and then filtered through a Millipore membrane with $0.45 \mu \mathrm{m}$ porosity.

\section{Spectrophotometry Analysis}

The total phenol contents of cocoa were determined using the Folin-Ciocalteu method (Chandra \& Mejia, 2004). Aliquats of the extract were taken in a $15 \mathrm{~mL}$ glass tube and made up to the volume of $1 \mathrm{~mL}$ with destilled water. Then $0.5 \mathrm{~mL}$ Folin-Ciocalteu reagent ( $1: 1$ with water) and $2.5 \mathrm{~mL}$ of sodium carbonate solution $(20 \%)$ were added sequentially in each tube. After vortexing, tubes were incubated at room temperature in the dark for $40 \mathrm{~min}$. Absorbance was measured at $725 \mathrm{~nm}$ againts the reagent blank. The amount of total phenolics was calculated as gallic acid and equivalent from a calibration curve.

\section{RESULTS AND DISCUSSION}

A major problem during micro-propagation is lethal browning caused by exudation of phenolic compounds (secondary metabolites) from excised portion of explants (Ahmad et al., 2013). Some of these exudates appear as a reaction to injury and/or infection. In tissue culture they appear after tissue excision and many times aggravated by growth media constituents. These condition eventually lead to growth inhibition or death of explants. Other types of phenolic exudates appear at the end of incubation period and are apparently product of dying cells (Seneviratne \& Wijesekara, 1996). The phenolic exudation is aided by light and autocatalytic.

Total phenolics, flavonoids and chatecin evolved in a similar way during tissue culture, irrespective of genotype and embryogenic capacity. They were abundant in flower and leaf induction, but their concentration increased during the process. However significant concentration of total phenol and flavonoids were observed in different calli, with non-embryogenic calli containing the smallest amount of phenolic and flavonoids. These compounds were intermediately concentrated in embryogenic Sulawesi 1 clone cultured under condition in which embryogenic capacity was expressed. The experimental result showed that phenolic compounds were changed during somatic embryogenesis processes.

The results of spectrophotometric analysis showed that the concentration of phenolic compounds and flavonoids obtained the highest at embryogenic callus phase (4.7 and 5.1\%) and the lowest concentration at the callus induction phase from leaf explants (0.67 and 2.1\%). Meanwhile, for the highest catechin concentration was observed at the formation of somatic embryo phase $(12.5 \%)$ and non embryogenic callus phase.

Browning on the callus first was observed 2 weeks after in culture, because at this stage the activity of peroxidase (POD) reaches a 

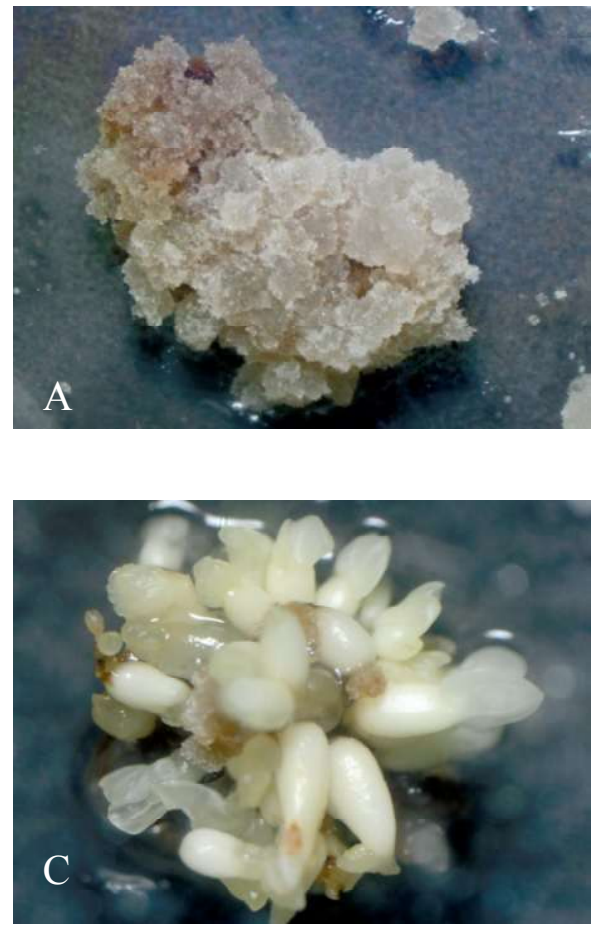
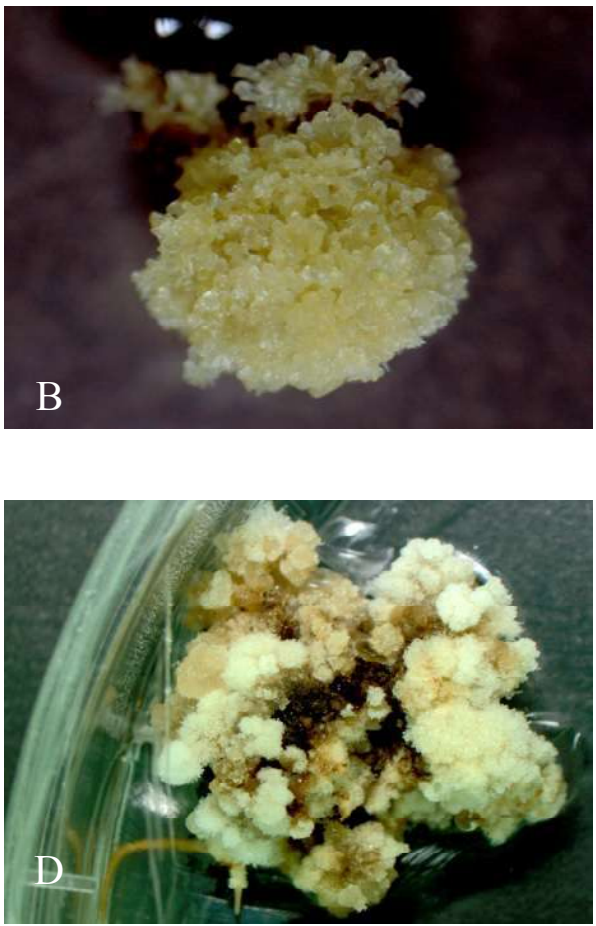

Figure 1. A. Non embryogenic calli from flower induction, B. Embryogenic calli, C. Somatic embryo, and D. Non embryogenic calli from leaves induction

Table 1. Concentrations of phenol, flavonoids and cathekin in some types of calli

\begin{tabular}{lccc}
\hline \multicolumn{1}{c}{ Samples } & \multicolumn{3}{c}{ Spectrofotometry analysis } \\
\cline { 2 - 4 } & Total of phenol, \% & Total of flavonoids, \% & Total of cathekin, $\%$ \\
\hline Callus from flower bud & $1.0 \pm 0.04$ & $3.2 \pm 0.18$ & $4.2 \pm 0.28$ \\
Embryogenic callus & $4.7 \pm 0.04$ & $5.1 \pm 0.06$ & Undetected \\
Somatic embryo & $1.2 \pm 0.04$ & $2.0 \pm 0.06$ & $12.5 \pm 0.34$ \\
Callus from leaves & $0.67 \pm 0.03$ & $2.1 \pm 0.09$ & $7.0 \pm 0.14$ \\
\hline
\end{tabular}

Note: Mean \pm SD

maximum and the growth rate started to decrease (Laukkanen et al., 2000).

Total polyphenol content was observed on Sulawesi 1 cocoa clone. Embryogenic and non-embryogenic callus were also compared. The percentage of callus production from flower tissue is $85 \%$, percentage of embryogenic callus $40 \%$, although the percentage of somatic embryo production from embryogenic callus was $70 \%$. The conservation of callus into somatic embryos followed by decline in phenol content and an increase in peroxidase. The synthesis kinetics for these compounds in calli, under different somatic embryogenesis conditions, revealed a higher concentration under nonembryogenic conditions. So that, phenolic compound can influence the production of calli and an absence of the phenolic compounds can enhance production of somatic embryo.

Low of cathechin regenerated somatic embryos. Total phenolics and flavonoids

PELITA PERKEBUNAN, Volume 31, Number 1, Edition April 2015 


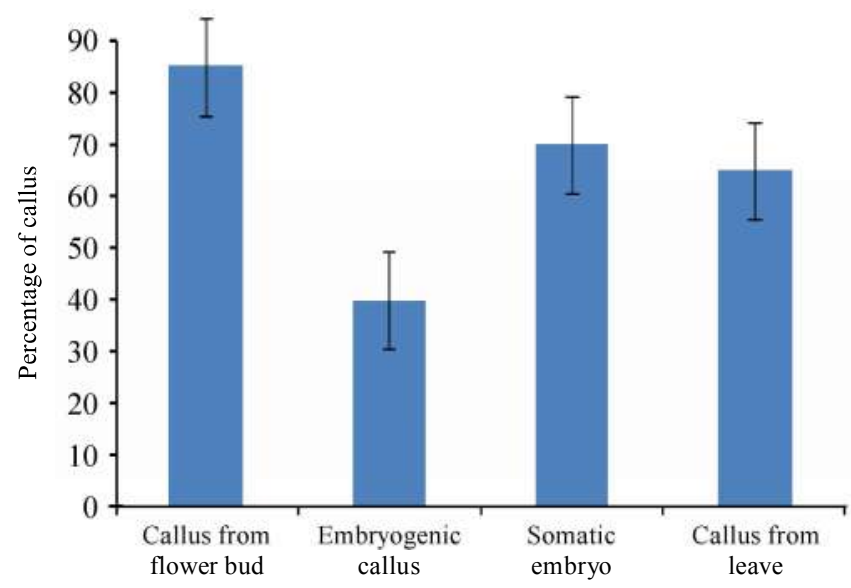

Figure 2. Percentages of in vitro propagation during somatic embryos development (error bean indicate SD)

evolved in similar way during formation of embryogenic calli. Their concentration decreased during the process. The accumulation of phenolics is directly influenced by in vitro propagation. Phenol can cause browning and necrosis of explants. The media without activated charcoal contained phenolic compounds and other metabolites inhibited embryogenesis and morphogenesis (Fridborg et al., 1978). The addition of PVPP into media can eliminate and prevent the browning.

It is known that cell death is correlated with elevated levels of peroxides during tissue browning, in addition many factors are able to induce browning after the explant treatment such as temperature and light intensity through the experiment. In some plants higher peroxidase activity is induced by mechanical injury, enviromental stress, $\mathrm{H}_{2} \mathrm{O}_{2}$ and polyphenols (Wei et al., 2004). When antioxidants were added to the plant tissue culture medium, they reacted with polyphenols and decreased the concentration of harmful compounds. Frequent subculturing to fresh medium may also assist so that toxic phenolic compounds do not hinder the activity of plant growth regulators on tissues (Youssief, 2009).
The aim of this experiment was to identify how phenolic compound has a relationship with embryogenic capacity. Phenolic compound was found at the calli formation from induction, embryogenic and somatic embryo production. Jabri et al. (1989) observed a relationship between callogenesis and embryogenic aptitude and the concentration of tannins in Sorghum bicolor. A tannin-poor variety regenerated somatic embryo. A variety moderately rich in tannins only produced calli, and a tannin rich variety barely produced any calli. At the cocoa callus level, during the callogenesis and somatic embryogenesis processes, no clear relationship was detected between the presence or absence of polyphenolics and embryogenic or non-embryogenic response. In date palm, El Hadrami (1995) distinguished between embryogenic calli and multiplying calli by the presence and accumulation of new flavones and flavonols. Embryogenic capacity, therefore, seemed to be associated with a balanced concentration of phenolics (Alemanno et al., 2003). Owing to the antioxidant nature of these molecules (Kroon \& Williamson, 1999) they are more related to stress condition than to embryogenic status itself. The more the 
tissues were stressed, the more of these substances were synthesized. Somatic embryogenesis could be expressed under less stressful conditions.

Accumulation of phenolic compounds in the explant can be referred as browning. Browning is a character of the appearance of brown or black color that often makes the absence of growth and development in plants or explants in tissue culture. Browning is a natural event that common in biological systems, a process of adaptive changes of the plant due to the influence of physical and biochemical (bruises, stripping, cutting, disease, or abnormal conditions).

Browning due to the accumulation of phenol called enzymatic browning. Browning can also occur because of chemical stimulation or if the explants environment provide chemicals that encourage the formation of phenolic compounds, such as, the high concentration of the auxin in the medium. In embryogenic callus explants, the accumulation of phenolic compounds have a higher concentration (4.7\%) compared to other explants (callus of interest of $1 \%$, $1.2 \%$ and somatic embryos from leaf callus $0.67 \%$ ). This can be correlated that, at this stage the use of auxin concentration is higher $\left(1.25 \mathrm{mg} \mathrm{L}^{-1}\right)$ compared to the other treatment medium.

\section{CONCLUSION}

Regeneration of callus into somatic embryos is followed by decreased levels of phenols and increased peroxidase. Synthesis kinetics for phenol compounds in callus, somatic embryogenesis under different conditions, revealed higher concentrations in non-embryogenic conditions. Absence of phenolic compounds can increase the production of somatic embryos.
In embryogenic callus explants, the accumulation of phenolic compounds has higher concentration compared to other explants.

\section{REFFERENCES}

Ahmad, I.; T. Hussain; I. Ashraf; M. Nafees; M.R. Maryam \& M. Iqbal (2013). Lethal effects of secondary metabolites on plant tissue culture. Journal of Agriculture and Enviromental Science, 13, 539-547.

Alemanno, L.; M. Berthouly \& N. MichauxFerriere (1996). Histology of somatic embryogenesis from floral tissues in Theobroma cacao L. Plant Cell Tissue and Organ Culture, 46, 187-194.

Alemano, L.; T. Ramos; A. Gargadenec; C. Andary \& N. Ferriere (2003). Localization and identification of phenolic compounds in Theobroma cacao L. somatic embryogenesis. Annuals of Botany, 92, 613-623.

Benson, E.E. (2000). In vitro plant recalcitrance: an introduction. In Vitro Cellular and Developmental Biology, 36, 141-148.

Chandra, S. \& E.G. Mejia (2004). Polyphenolic compounds, antioxidant capacity and quinone reductase activity of an aqueous extract of ardisia compressa in comparision to mate (Ilex paraguaiensis) and green teas (Camellia sinensis). Journal of Agricultural and Food Chemistry, 52, 3583-3589.

Compton, M.E. \& J.E. Preece (1986). Exudation and explant establishment. International Association of Plant Tissue Culture Newsletter, 50, 9-18.

El Hadrami, I. (1995). L'embryogenese somatique chez Phoenix dactylifera $\mathrm{L}$. Quelques facteurs limitants et marqueurs bichimiques. These de Doctorat d'Etat, Faculte des Sciences Semlalia, Universite Cadi Ayyad, Marrakech, Morroco. 
Figueira, A. \& J. Janick (1995). Somatic embryogenesis in cacao (Theobroma cacao L.). p. 291-310. In: S. Jain, P. Gupta \& R. Newton (Eds.). Somatic Embryogenesis in Woody Plants, vol. 2. Kluwer Academic Publishers. The Netherlands.

Fridborg, G.; M. Pederson; L.E. Landstron \& T. Ericsson (1978). The effect of activated charcoal on tissue culture: Absorption of metabolites inhibiting morphogenesis. Physiology Plantarum, 43, 104-106.

Galston, A.W.; S. Lavee \& B.Z. Siegel (1968). The induction and repression of peroxidase isozymes by 3-indoleacetic acid. p. 455. In: F. Wightman \& G. Setterfield (Ed). Biochemistry and Physiology of Plant Growth Substances. The Runge Press, Ottawa.

Griffiths, L.A. (1958). Phenolic acids and flavonoids of Theobroma cacao L.; separation and identification by paper chromatography. Biochemical Journal, 70, 120-125.

Jabri, A.; R. Chaussat; M. Jullien; Y. Le Deunff (1989). Aptitude a la collagenese et a i 'embragenese somatiquo de fragments foliares de trois varietes de sorgho (Sorgum bicolor L. Moench) avec et sans tannis. Agronomie, 9, 101-107.

Keskitalo, M.K. (1999). Exploring Biodiversty to Enhance Bioactivity in the Genus Tanacetum Through Protoplast Fusion. Thesis, University of Helsinki. Finland.

Kim, H. \& P.G. Keeney (1983). Method of analysis for epicatechin in cocoa beans by high performance liquid chromatography. Journal of Food Science, 48, 548-551.

Kroon, P.A. \& G. Williamson (1999) Hydroxycinnamates in plants and food: current and future perspectives. Journal of Science and Food Agriculture, 79, 355-361.

Laukkanen, H.; L. Rautiainen; E. Taulavuori \& A. Hohtola (2000). Changes in cellular structures and enzymatic activities during browning of Scots pine callus derived from mature buds. Tree Physiology, 20, 467-475.

Lindfors, A.; H. Kuusela; A. Hohtola \& S. KupilaAhvenniemi (1990). Molecular correlates of tissue browning and deterioration in Scots pine calli. Biology Plantarum, 32, 171-180.

Li, Z.; A. Traore; S. Maximova \& M. Guiltinan (1998). Somatic embryogenesis and plant regeneration from floral explants of cocoa (Theobroma cacao L.) using thidiazuron. In Vitro Cellular and Developmental Biology, 34, 293-299.

Lopez-Baez, O.; H. Bollon; A.B. Eskes \& V. Petiard (1993). Embryogenese somatique de cacaoyer Theobroma cacao L. a partir de pieces florales. Compte Rendus d l'Academie des Sciences, Serie 6, 316, 579-584.

Marks, T.R. \& S.E. Simpson (1990). Reduced phenolic oxidation at culture initiation in vitro following the exposure of fieldgrown stock plants to darkness or low levels of irradiance. Journal of Horticultural Science, 65, 103-111.

Scalbert, A.; B. Monties \& I.L. Favre (1988). Polyphenols of Quercus robur: adult tree and in vitro growth calli and shoots. Phytochemistry, 27, 3483-3488.

Seneviratne, P. \& G.A.S. Wijesekara (1996). The problem of phenolic exudates in in vitro cultures of mature Hevea brasiliensis. Journal of Plantation Crops, 24, 54-62.

Wei, C.; J. Li \& R.E. Bumgarner (2004). Sample size for detecting differentially expressed genes in microarray experiments. BMC Genomics, 5, 1-10.

Youssief, E.Y. (2009). In Vitro Propagation of Strawberry (Fragaria annanasa Duch.) Through Organogenesis via Runner Tips. Thesis. The Islamic UniversityGaza, Faculty of Science, Master of Biological Sciences.

$* * 0 * *$ 